\title{
Cabergoline treatment for recurrent Cushing's disease during pregnancy
}

\author{
Afif Nakhleh, Leonard Saiegh, Maria Reut, Mohammad Sheikh Ahmad, \\ Irit Wirsansky Pearl, Carmela Shechner
}

Endocrinology Department, Bnai Zion Medical Center, Haifa, Israel

\begin{abstract}
OBJECTIVE: Cushing's disease during pregnancy is associated with an increased risk for maternal and fetal complications. In recurrent Cushing's disease following transsphenoidal surgery, and when re-operation is not feasible, medical treatment is usually considered. Cabergoline was found to be effective in reducing hypercortisolism in Cushing's disease. Evolving data concerning the safety of cabergoline use during pregnancy show no significant increase in the rate of complications during pregnancy or the postnatal period. METHODS: We report a 29-year-old woman, gravida 0 , para 0 , with recurrent Cushing's disease, three years after transsphenoidal resection of pituitary ACTH-secreting macroadenoma. Repeated MRI revealed an empty sella with a small gadolinium-enhancing lesion, suspected to be an adenoma remnant on the medial wall of the right cavernous sinus. As the patient was not willing to undergo repeat surgical intervention, treatment with cabergoline was initiated, with a gradual dose titration up to $3.5 \mathrm{mg} /$ week. Clinical improvement ensued, and 4 months later, she conceived spontaneously. After discussing treatment options with the patient, cabergoline treatment at a dose of $2 \mathrm{mg} /$ week was continued throughout pregnancy. RESULTS: The patient showed complete clinical remission during pregnancy. Consecutive tests of 24-h urinary free cortisol concentration were not found to be elevated. Pregnancy and delivery were uneventful except for mild hypothyroidism observed during the second trimester. At full term the patient delivered a healthy female infant, by an elective cesarean section. CONCLUSION: This case report demonstrates that cabergoline may be an effective and safe therapeutic option for the treatment of Cushing's disease during pregnancy.
\end{abstract}

Key words: Cabergoline, Cushing's disease, Pregnancy

Address for correspondence:

Dr. Afif Nakhleh, Endocrinology Department, Bnai Zion

Medical Center, 47 Golomb St, Haifa 31048, Israel;

Tel.: +972-4-8359931, E-mail: anakhleh@yahoo.com

Received: 18-03-2016, Accepted: 26-05-2016

\section{CASE REPORT}

A 29 year-old woman, gravida, 0 para 0 , was referred to our outpatient clinic with a 3-year history of oligomenorrhea, unexplained weight gain of 20 
$\mathrm{kg}$, mood changes, and general weakness. She had been trying to conceive spontaneously for 2 years, but to no avail.

Physical examination revealed the following: weight $96 \mathrm{~kg}$, height $163 \mathrm{~cm}$, BMI $36.1 \mathrm{~kg} / \mathrm{m}^{2}$, normal blood pressure, central abdominal obesity, abdominal striae, and male pattern hirsutism scattered over the cheeks and the chest. Laboratory endocrine evaluation revealed an elevated 24-hour urinary free cortisol concentration (413 mcg/24h; reference range: $20-90 \mathrm{mcg} / 24 \mathrm{~h}$ ); serum cortisol concentration taken at 8:00 A.M. after $1 \mathrm{mg}$ dexamethasone given at 23:00pm was $8.8 \mathrm{mcg} / \mathrm{dL}$. Basal morning (8 A.M.) plasma ACTH concentration was elevated (22.7 pmol/L; reference range: 1.11-10 $\mathrm{pmol} / \mathrm{L}$ ). The patient had normal thyroid function tests (TSH $2.95 \mathrm{mcg} / \mathrm{mL}$; reference range: $0.4-4 \mathrm{mcg} / \mathrm{mL}$, FT4 $1.24 \mathrm{ng} / \mathrm{dl}$; reference range: $0.8-1.9 \mathrm{ng} / \mathrm{dL}$ ) and a normal prolactin level $(9.3 \mathrm{ng} / \mathrm{mL}$, reference range: 1.9-25 ng/mL). Serum LH and FSH concentrations were within the normal range $(3.98 \mathrm{mIU} / \mathrm{mL}$ and 5.45 $\mathrm{mIU} / \mathrm{mL}$ respectively). Fasting plasma glucose was $77 \mathrm{mg} / \mathrm{dL}$, plasma sodium $141 \mathrm{meq} / \mathrm{L}$, (reference range: $135-145 \mathrm{meq} / \mathrm{L}$ ), and potassium $3.9 \mathrm{meq} / \mathrm{L}$ (reference range: $3.5-5.1 \mathrm{meq} / \mathrm{L}$ ).

On gadolinium-enhanced T1-weighted MRI, the patient was found to harbor a hyperintense pituitary macroadenoma measuring $20 * 15 * 19 \mathrm{~mm}$, with a superiorly displaced optic chiasm, deviation of the pituitary stalk to the right, and no signs of cavernous sinus involvement (Figure 1). Visual fields were normal.

The clinical, laboratory, and imaging findings were compatible with Cushing's disease due to pituitary macroadenoma. Subsequently, the patient underwent endoscopic-assisted transsphenoidal resection of the adenoma. No complications arose during the operative and postoperative period. Histopathological examination of the surgical specimen was consistent with corticotroph-cell adenoma. Adenoma cells stained positive for $\mathrm{ACTH}$ and were negative for prolactin, LH, FSH, and TSH. MIB-1 staining was positive in $1-2 \%$ of tumor cells. Laboratory tests on the first postoperative day revealed a low plasma cortisol level (plasma cortisol level 24 hours postoperativly was $3.4 \mathrm{mcg} / \mathrm{dL}$ ). As the patient had postoperative hypoadrenalism, treatment with hydrocortisone was

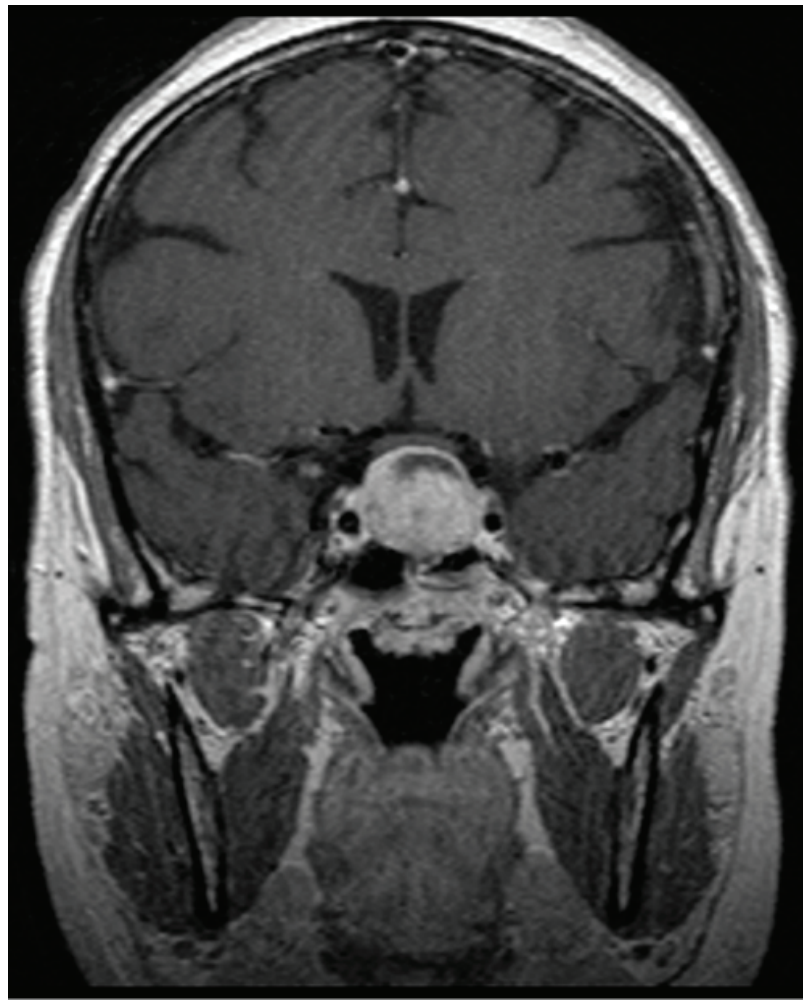

Figure 1. Coronal gadolinium-enhanced T1-weighted MRI image shows a hyperintense pituitary macroadenoma with cystic component. The optic chiasm is displaced superiorly.

initiated and was gradually tapered off over a 9-month period as adrenal function tests became normal.

Clinical remission of Cushing's disease ensued, accompanied by normalization of urinary free cortisol (24-h urinary free cortisol concentration was 30 $\mathrm{mcg} / 24 \mathrm{~h}, 28 \mathrm{mcg} / 24 \mathrm{~h}$, and $55 \mathrm{mcg} / 24 \mathrm{~h}$ at 3,6 , and 12 months post-surgery, respectively; reference range: 20-90 mcg/24h).

The patient was lost to follow-up. However, 3 years after the transsphenoidal surgery, she presented again with a 6-month history of weight gain, swelling of the legs, hirsutism, irregular menses, and inability to conceive. Endocrine laboratory evaluation revealed: 24-h urinary free cortisol concentration of $131 \mathrm{mcg} / 24 \mathrm{~h}$ (reference range: $20-90 \mathrm{mcg} / 24 \mathrm{~h}$ ), basal morning ACTH concentration of $22 \mathrm{pmol} / \mathrm{L}$ (reference range: $1.11-10 \mathrm{pmol} / \mathrm{L}$ ), while serum cortisol measured at 8:00 A.M. after $1 \mathrm{mg}$ dexamethasone administration at 23:00 PM was $6.2 \mathrm{mcg} / \mathrm{dL}$. In light of the above, recurrent Cushing's disease was diagnosed. 
Repeated MRI revealed an empty sella, with a small gadolinium-enhancing lesion, suspected to be an adenoma remnant on the medial wall of the right cavernous sinus (Figure 2).

Since the patient was not willing to undergo a repeat surgical intervention, treatment with cabergoline was initiated, with a gradual dose titration up to 3.5 $\mathrm{mg} /$ week. Shortly after the initiation of cabergoline, clinical improvement was observed and the patient conceived spontaneously 4 months after the cabergoline treatment had started.

After discussing treatment options with the patient, a decision was reached to proceed with cabergoline during pregnancy. The cabergoline dose was gradually titrated down from a dose of $3.5 \mathrm{mg} /$ week to a dose of $2 \mathrm{mg} /$ week reached at 7 weeks gestation, and was maintained at this level during the course of pregnancy.

Throughout pregnancy, the patient showed clinical remission, while consecutive tests of 24-h urinary free cortisol concentration were not found to be elevated (24-h urinary free cortisol concentration was $67 \mathrm{mcg} / 24 \mathrm{~h}$, and $74 \mathrm{mcg} / 24 \mathrm{~h}$ at 24 weeks and 28

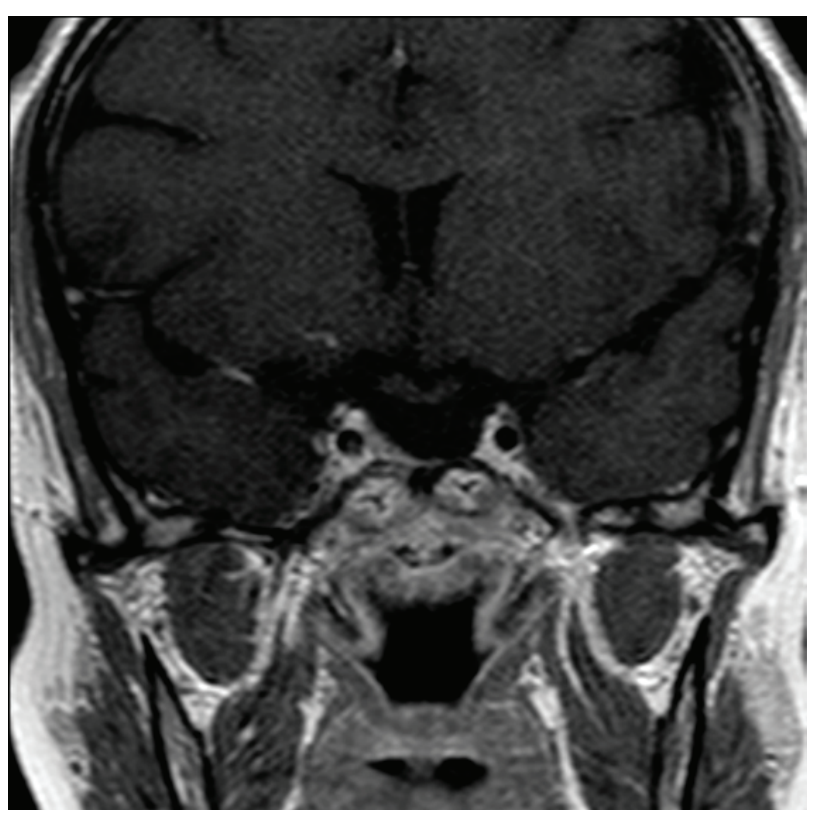

Figure 2. Coronal gadolinium-enhanced T1-weighted MRI image shows an empty sella with a small enhancing lesion suspected to be adenoma remnant on the medial wall of the right cavernous sinus. weeks, respectively; reference range: $20-90 \mathrm{mcg} / 24 \mathrm{~h}$ ).

The course of pregnancy was uneventful except for mild hypothyroidism, which was observed in the $20^{\text {th }}$ week of pregnancy. The thyroid function test revealed a TSH of $5.99 \mathrm{mIU} / \mathrm{L}$ (reference range: $0.27-4.2 \mathrm{mIU} / \mathrm{L}$ ), FT4 of $12.77 \mathrm{pmol} / \mathrm{L}$ (reference range: $12-22 \mathrm{pmol} / \mathrm{L}$ ), FT3 of $3.85 \mathrm{pmol} / \mathrm{L}$ (reference range: $3.1-6.8 \mathrm{pmol} / \mathrm{L}$ ), thus levothyroxine at a dose of $350 \mathrm{mcg} /$ week was initiated.

The oral glucose $(100 \mathrm{gr})$ tolerance test at the $28^{\text {th }}$ week of pregnancy was normal (fasting glucose was $82 \mathrm{mg} / \mathrm{dL}, 30 \mathrm{~min}$ post-challenge glucose was 107 $\mathrm{mg} / \mathrm{dL}, 60 \mathrm{~min}$ post challenge glucose was $99 \mathrm{mg} / \mathrm{dL}$, and $120 \mathrm{~min}$ post-challenge glucose of $92 \mathrm{mg} / \mathrm{dL}$ ).

At full term, the patient delivered a healthy female infant, weighing 3370 grams, by an elective cesarean section.

Four months after delivery the patient decided voluntarily to stop taking cabergoline; 6 months later she presented at our outpatient clinic with recurrent clinical and biochemical Cushing's syndrome. 24-h urinary free cortisol concentration was elevated (216 $\mathrm{mcg} / 24 \mathrm{~h}$; reference range: $20-90 \mathrm{mcg} / 24 \mathrm{~h}$ ) and cabergoline at a dose of $3 \mathrm{mg} /$ week was reinstituted.

\section{DISCUSSION}

Pregnancy is rare in patients with Cushing's syndrome given the high prevalence of menstrual irregularities, occurring in up to $80 \%$ of patients according to a series of 45 women with newly diagnosed Cushing's disease. ${ }^{1}$

Cushing's syndrome is associated with several maternal morbidities including: hypertension, impaired glucose tolerance, diabetes, and preeclampsia. It is also associated with an increased risk for fetal prematurity, intrauterine growth retardation, spontaneous abortions, and stillbirths. ${ }^{2}$ Although urinary free cortisol rises during normal pregnancy, it is considered to be the best screening method for Cushing's syndrome during pregnancy. ${ }^{3}$

The data reported in the literature are not sufficiently extensive to allow a comparison of the outcomes for treated versus untreated patients, especially given the low incidence of Cushing's disease in pregnant 
women. Nonetheless, the literature points to a trend towards an increased live births rate in treated compared with untreated pregnancies. ${ }^{4}$

Transsphenoidal resection of an ACTH-secreting pituitary adenoma has been performed successfully during the second trimester of pregnancy and is considered the treatment of choice for Cushing's disease. ${ }^{5}$

In cases of recurrent hypercortisolism after transsphenoidal resection and, when repeated surgery is not feasible, medical treatment should be considered.

Metyrapone, which inhibits the last step in cortisol biosynthesis (through inhibition of 11 beta hydroxylase), has been the drug most often used in pregnancy.

Metyrapone appears to be effective in suppressing hypercortisolism in some of the reported cases without teratogenic effects. However, it may lead to hypertension, predisposing the pregnant patient to pre-eclampsia, and can increase the risk of pre-term delivery. ${ }^{6}$

In a recent review, Lim et al. reported 13 pregnant women with Cushing's syndrome managed with metyrapone alone, the majority of whom were treated in the second to the third trimester. Over half of these women delivered before the 34th week of gestation, three women suffered from pre-eclampsia, and two women had placental abruption. One stillbirth and two neonatal deaths occurred. The major neonatal complications were related to prematurity, including respiratory distress and neonatal jaundice. A single case of neonatal adrenal insufficiency was also reported. ${ }^{6}$

Ketoconazole, an antimycotic agent with antisteroidogenic properties, has been used in four cases of Cushing's syndrome during pregnancy and did not result in adverse fetal or maternal events. In two of the four cases ketoconazole was used during the first trimester of pregnancy. ${ }^{7-10}$

In the rat, ketoconazole crosses the placenta and is teratogenic, and in humans it is classified as FDA category C. A recent population-based case-control study did not find a higher rate of congenital abnormalities in infants born to mothers who had received oral ketoconazole treatment during pregnancy; however, the number of exposed cases and controls was too small to allow for solid conclusions. ${ }^{11}$
Moreover, ketoconazole has antiandrogenic effects through inhibition of aromatase activity. Thus, concerns still remain regarding its use during pregnancy and more stratified studies are needed to establish its safety.

In their consensus statement, published in 2008, Biller et al. argued that when treatment is considered, metyrapone rather than ketoconazole is recommended. ${ }^{5}$ Data are scarce regarding the effect of Mitotane treatment on the human fetus and its safety during pregnancy has yet to be demonstrated. ${ }^{12,13}$

Functional D2 receptors were found to be expressed in about $80 \%$ of corticotroph pituitary adenomas. ${ }^{14}$ It has been demonstrated that cabergoline, at a median dose of $3.5 \mathrm{mg} /$ week (maximal dose ranging from $1-7 \mathrm{mg} /$ week), is effective in controlling cortisol secretion for at least 1-2 years without producing major side effects in $40 \%$ of patients with Cushing's disease unsuccessfully treated by surgery..$^{15} \mathrm{~A}$ recent study also confirmed the effectiveness of cabergoline in producing a long-term (mean of 37 months) complete response in $30 \%$ of patients with persistent or recurrent Cushing's disease after unsuccessful pituitary surgery. ${ }^{16}$

Several studies have assessed dopamine agonists' safety throughout pregnancy. The safety of bromocriptine in pregnancy, both for the mother and the fetus, was demonstrated in earlier studies testing more than 6,000 pregnancies. No increased rates of spontaneous abortions or neonatal malformations compared with the normal population was demonstrated. ${ }^{17-19}$ Albeit scarce, studies regarding the safety of cabergoline in pregnancy showed no increased incidence of complications in the mother or the fetus and it is currently an FDA pregnancy category B drug. One observational study of a total of 380 pregnancies suggested that cabergoline treatment at a median dose of $1 \mathrm{mg} /$ week (ranging from $\leq 0.25 \mathrm{mg} /$ week to $5 \mathrm{mg} /$ week) at the time of conception and during early pregnancy is not likely to induce an increase in the risk of miscarriage or of fetal malformation. ${ }^{20}$ Another retrospective study included 100 pregnancies in women conceiving under cabergoline treatment for hyperprolactinemia and receiving the drug at a median dose of $0.5 \mathrm{mg} /$ week for a median period of 4 weeks during early pregnancy. This study showed 
a $10 \%$ incidence of spontaneous miscarriage, $3 \%$ of termination of pregnancy for fetal malformation and $3.4 \%$ of neonatal malformation. These rates are similar to those reported in the general population. ${ }^{21}$

Furthermore, one study by Stalldecker et al. was conducted on a sample of 103 pregnancies of women with hyperprolactinemia, the majority of whom had received cabergoline at a median dose of $0.5 \mathrm{mg} /$ week (ranging from 0.125 to $5 \mathrm{mg} /$ week) during the first trimester of pregnancy and the rest until the second trimester. In this study, the researchers did not find a higher incidence of spontaneous abortions, preterm deliveries or neonatal malformations than in the normal population. ${ }^{22}$ Cabergoline treatment throughout the whole pregnancy period is less common. There are only about 15 reported pregnancies of patients suffering from macroprolactinomas who used cabergoline throughout pregnancy and they did not show any adverse effects. ${ }^{23}$

To our knowledge, no large study has as yet tested the safety of high-dose cabergoline during pregnancy. A recent case report described a 29-year-old woman with Cushing's disease who underwent a noncurative transsphenoidal pituitary surgery and who conceived spontaneously one year after initiating cabergoline and was maintained on high-dose cabergoline requiring an incremental increase up to $10 \mathrm{mg}$ per week. She had an uncomplicated antenatal course and went into labor spontaneously. ${ }^{24}$

In our patient with Cushing's disease during pregnancy, we made an effort to avoid the potential risk for adverse maternal or fetal outcomes associated with untreated Cushing's disease and the high-probability potential hazard of metyrapone treatment during pregnancy. We thus decided to continue treatment with cabergoline during pregnancy, weighing its effectiveness in reversal of hypercortisolism and its minimal potential adverse effects. As explicated earlier, most studies have examined low-dose cabergoline (average of $1 \mathrm{mg} /$ week) safety in pregnancy and have shown no increased incidence of complications in the mother or the fetus. We gradually decreased the cabergoline dose from $3.5 \mathrm{mg} /$ week down to a dose of $2 \mathrm{mg} /$ week, reached at 7 weeks gestation, and cabergoline was maintained at this dose throughout pregnancy. Cabergoline proved to be effective dur- ing the course of our patient's pregnancy with the patient revealing no signs of clinical recurrence and displaying normal consecutive 24-h urinary free cortisol concentrations during treatment. The $28^{\text {th }}$ week oral glucose tolerance test was normal, further indicating full control of hypercortisolism attributed to cabergoline. Furthermore, no maternal or fetal complications were evident.

In conclusion, this case report demonstrates that cabergoline may be an effective and safe therapeutic option for the treatment of Cushing's disease during pregnancy. Further studies are needed to delineate the role of cabergoline treatment and to conclusively confirm the safety it has to date shown in pregnant women with Cushing's disease.

\section{DECLARATION OF INTEREST}

The authors declare that there are no conflicts of interest.

\section{FUNDING}

This research did not receive any specific grant from any funding agency in the public, commercial or not-for-profit sector.

\section{REFERENCES}

1. Lado-Abeal J, Rodriguez-Arnao J, Newell-Price JD, et al, 1998 Menstrual abnormalities in women with Cushing's disease are correlated with hypercortisolemia rather than raised circulating androgen levels. J Clin Endocrinol Metab 83: 3083.

2. Lindsay JR, Jonklaas J, Oldfield EH, Nieman LK, 2005 Cushing's syndrome during pregnancy: personal experience and review of the literature. J Clin Endocrinol Metab 90: 3077-3083.

3. Nieman LK, Biller BM, Findling JW, et al, 2008 The diagnosis of Cushing's syndrome: an Endocrine Society Clinical Practice Guideline. J Clin Endocrinol Metab 93: 1526-1540.

4. Lindsay JR, Jonklaas J, Oldfield EH, Nieman LK, 2005 Cushing's syndrome during pregnancy: personal experience and review of the literature. J Clin Endocrinol Metab 90: 3077-3083.

5. Biller BM, Grossman AB, Stewart PM, et al, 2008 Treatment of adrenocorticotropindependent Cushing's syndrome: a consensus statement. J Clin Endocrinol Metab 93: 2454-2462.

6. Lim WH, Torpy DJ, Jeffries WS, 2013 The medical 
management of Cushing's syndrome during pregnancy. Eur J Obstet Gynecol Reprod Biol 168: 1-6.

7. Prebtani AP, Donat D, Ezzat S, 2000 Worrisome striae in pregnancy. Lancet 355: 1692.

8. Amado JA, Pesquera C, Gonzalez EM, Otero M, Freijanes J, Alvarez A, 1990 Successful treatment with ketoconazole of Cushing's syndrome in pregnancy. Postgrad Med J 66: 221-223.

9. Berwaerts J, Verhelst J, Mahler C, Abs R, 1999 Cushing's syndrome in pregnancy treated by ketoconazole: case report and review of the literature. Gynecol Endocrinol 13: $175-182$.

10. Boronat M, Marrero D, López-Plasencia Y, Barber M, Schamann Y, Nóvoa FJ, 2011 Successful outcome of pregnancy in a patient with Cushing's disease under treatment with ketoconazole during the first trimester of gestation. Gynecol Endocrinol 27: 675-677.

11. Kazy Z, Puho' E, Czeizel AE, 2005 Population-based case-control study of oral ketoconazole treatment for birth outcomes. Congenit Anom (Kyoto) 45: 5-8.

12. Leiba S, Weinstein R, Shindel B, et al, 1989 The protracted effect of o,p'-DDD in Cushing's disease and its impact on adrenal morphogenesis of young human embryo. Ann Endocrinol (Paris) 50: 49-53.

13. Tripto-Shkolnik L, Blumenfeld Z, Bronshtein M, Salmon A, Jaffe A, 2013 Pregnancy in a patient with adrenal carcinoma treated with mitotane: A case report and review of literature. J Clin Endocrinol Metab 98: 443- 447.

14. Pivonello R, Ferone D, de Herder WW, et al, 2004 Dopamine receptor expression and function in corticotroph pituitary tumors. J Clin Endocrinol Metab 89: 2452-2462.

15. Pivonello R, De Martino MC, Cappabianca P, et al,
2009 The medical treatment of Cushing's disease: effectiveness of chronic treatment with the dopamine agonist cabergoline in patients unsuccessfully treated by surgery. J Clin Endocrinol Metab 94: 223-230.

16. Godbout A, Manavela M, Danilowicz K, Beauregard H, Bruno OD, Lacroix A, 2010 Cabergoline monotherapy in the long-term treatment of Cushing's disease. Eur J Endocrinol 163: 709-716.

17. Turkalj I, Braun P, Krupp P, 1982 Surveillance of bromocriptine in pregnancy. JAMA 247: 1589-1591.

18. Krupp P, Monka C, 1987 Bromocriptine in pregnancy: safety aspects. Klin Wochenschr 65: 823-827.

19. Weil C, 1986 The safety of bromocriptine in hyperprolactinaemic female infertility: a literature review. Current Medical Research and Opinion 10: 172-195.

20. Colao A, Abs R, Bárcena DG, Chanson P, Paulus W, Kleinberg D, 2008 Pregnancy outcomes following cabergoline treatment: extended results from a 12-year observational study. Clin Endocrinol (Oxf) 68: 66-71.

21. Lebbe M, Hubinont C, Bernard P, Maiter D, 2010 Outcome of 100 pregnancies initiated under treatment with cabergoline in hyperprolactinaemic women. Clin Endocrinol 73: 236-242.

22. Stalldecker G, Mallea-Gil MS, Guitelman M, 2010 Effects of cabergoline on pregnancy and embryo-fetal development: Retrospective study on 103 pregnancies and a review of the literature. Pituitary 13: 345-350.

23. Glezer A, Bronstein MD, 2014 Prolactinomas, cabergoline, and pregnancy. Endocrine 47: 64-69.

24. Woo I, Ehsanipoor RM, 2013 Cabergoline therapy for cushing disease throughout pregnancy. Obstet Gynecol 122: 485-487. 